\title{
Comparison of Precipitable Water Derived from Ground-Based GPS Measurements with Radiosonde Observations over the Korean Peninsula
}

\author{
Ha-Taek KWON \\ School of the Earth and Environmental Sciences, Seoul National University, Seoul, Korea \\ Tetsuya IWABUCHI \\ COSMIC Program Office, University Corporation for Atmospheric Research, Boulder, Colorado, USA \\ and \\ Gyu-Ho LIM \\ School of the Earth and Environmental Sciences, Seoul National University, Seoul, Korea
}

(Manuscript received 9 January 2007, in final form 30 July 2007)

\begin{abstract}
Precipitable water (PW) obtained from a permanent ground-based Global Positioning System (GPS) network on the Korean Peninsula was evaluated by using radiosonde measurements for two years. The GPS-derived PW is also validated using 5-min and 2-hourly troposphere products from International GNSS Service (IGS).

The GPS-derived PW from our analysis and the IGS products were reasonably consistent with mean bias (Ours minus IGS products) of $-0.27 \mathrm{~mm}$ and a standard deviation of $0.78 \mathrm{~mm}$.

The PW derived from radiosonde measurement (radiosonde PW) shows dry bias relative to GPSderived PW, where the mean bias (GPS minus radiosonde) is $1.50 \mathrm{~mm}$ with a standard deviation of $2.45 \mathrm{~mm}$. We also found systematic bias in radiosonde PW depending on the radiosonde launch time. At the site with 6-hourly high temporal resolution soundings, the bias is greater during day (0900 and 15 LST) than at night (2100 and $0300 \mathrm{LST}$ ) with a difference of $1.34 \mathrm{~mm}$ in the maximum. In addition, our results show the dependency of error statistics on the absolute amount of PW and seasons. The bias increased for large amounts of PW especially in the daytime. Standard deviation tended to increase under humid conditions, but does not vary with observation time. The possible bias in GPS-derived PW caused by un-modeled phase center variation is also simulated in this study. Most phase observation errors are attributed to multi-path effects caused by the structure of monuments, where the errors are relatively small against the dry biases found in radiosonde PW.

Our results addressed the accuracy of GPS-derived PW with reasonable quality and showed strong temporal and spatial variability of PW due to geographic location. These results suggest that GPSderived PW produced by the Korean regional GPS network has great potential to be used for various meteorological applications and could also contribute global GPS climatology.
\end{abstract}

Corresponding Author: Gyu-Ho Lim, School of Earth and Environmental Sciences, College of Natural Sciences, Seoul National University, Seoul 151-747, Korea.

E-mail: gyuholim@snu.ac.kr

(C) 2007, Meteorological Society of Japan

\section{Introduction}

Since the emergence of a new technique to retrieve PW from ground-based GPS observation, atmospheric PW can be estimated with an accuracy of about $1.5 \mathrm{~mm}$ or better and temporal 
resolution of about 30 min (Rocken et al. 1993, 1995; Duan et al. 1996). Following these promising results, numerous meteorological studies using PW derived from GPS measurements have been conducted and show encouraging results in various fields of meteorology, especially for improving moisture fields of numerical weather prediction from development (Kuo et al. 1993) to operational use (Gutman et al. 2003), including validating satellite and reanalysis data (Dietrich et al. 2004), and monitoring climate change (Yuan et al. 1993; Gradinarsky et al. 2002).

One of the key elements of information required to apply GPS-derived PW in meteorology, especially for numerical weather prediction models, is accurate statistical characteristics of GPS-derived PW. Previous research has addressed this issue by comparing GPS-derived PW with other independent measurements from water vapor radiometer, radiosonde, and so on. However, most studies were conducted in relatively dry regions, where PW averages $20 \mathrm{~mm}$ or less (Emardson et al. 1998; Tregoning et al. 1998). A few studies examined the accuracy of GPS-derived PW in humid regions and reported higher water vapor variability than in dry regions. Ohtani et al. (2000) reported that differences between GPS-derived PW and PW computed from radiosonde sounding was $3.7 \mathrm{~mm}$ in terms of $\mathrm{rms}$ (root mean square) based on a half year of measurements in the Japanese Islands. Liou et al. (2001) investigated PW sensing using GPS observations in near tropics (Taiwan) for one week, and they noted that the accuracy of absolute GPSderived PW should be examined in humid regions where the atmospheric water vapor burden is higher and more inhomogeneous for longer periods.

In this paper we address this issue by using the GPS-derived PW from the Korean GPS network for two years. The Korean Peninsula (Fig. 1 ) is located at the eastern edge of the Eurasian Continent, which is under the strong influence of Asian monsoons and surrounded by seas on three sides. This geographic location causes extreme spatial and temporal variability of $\mathrm{PW}$ at the seasonal time scale, ranging from $5 \mathrm{~mm}$ in the winter to over $70 \mathrm{~mm}$ for the rainy season.

There are approximately eighty permanent GPS stations on the Korean Peninsula and the GPS network has great potential for sensing atmospheric water vapor with high temporal and spatial resolution, like the GEONET (GPS Earth Observation NETwork) in Japan (Iwabuchi et al. 2000). However, the basic precision and features of PW estimated by GPS measurements in Korea have not been reported. There is also a need to evaluate the accuracy of PW derived from the Korean GPS network in order to develop further GPS-derived PW applications. Such evaluations of GPSderived $\mathrm{PW}$ in regional networks throughout the world may contribute to future meteorological research and applications using global ground-based GPS data.

We investigated the accuracy of GPS-derived PW by comparing it with PW estimated by radiosonde soundings, including 6-hourly high temporal radiosonde observations for two years on the Korean Peninsula. We compared GPSderived PW estimated by different software to examine the effect of analysis strategy. We also validated the GPS-derived PW from our own processing using IGS troposphere products with 5-min and 2-hour time intervals for two available IGS stations.

Descriptions for the dataset and analysis method are given in Section 2. Analysis results are described in Section 3, and possible errors in GPS-derived PW are discussed in Section 4. General summary and discussions are presented in Section 5.

\section{Dataset and analysis}

\subsection{Korean GPS network and GPS observation data}

At present over eighty ground-based GPS stations are maintained in Korea by several institutions, mainly for surveying, positioning, and monitoring crust deformation, and the number of stations is steadily increasing. Figure 1 shows the locations of GPS sites. Stations are spaced at an average distance of about $30 \mathrm{~km}$. The Trimble 4000SSI receiver and choke ring antenna (TRM29659.00) types are the most common, and monuments similar to GEONET are used in the Korean GPS network.

We selected three GPS stations that are close to radiosonde stations (SKCH, JEJU and SUWN) and two IGS stations (SUWN and DAEJ). The limited selection of GPS stations is due to consideration of horizontal distance be- 
tween GPS and radiosonde stations. Four IGS stations (LHAS, KHAJ, TNML and TSKB) in the eastern Eurasian Continent (Fig. 1) were also used for Bernese processing with a double difference strategy to estimate absolute ZTD (Beutler et al. 2000). The AOAD/M_T antenna is used for three IGS stations (LHAS, TNML and TSKB) and the JPSREGANT_SD_E an-

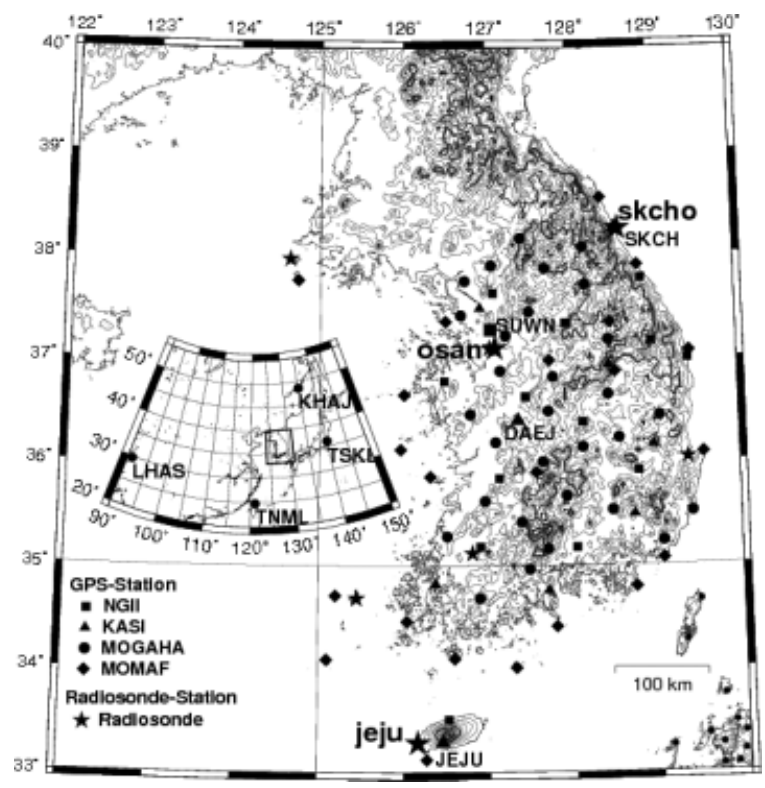

Fig. 1. Location of GPS stations on the Korean Peninsula. Symbols (except star shapes) represent GPS stations and different symbol shapes indicate different institutes that operate the stations. Stars are radiosonde stations. Symbols with station name indicate GPS and radiosonde stations used in this study. Small circles on the right portion of the figure represent some of the GEONET sites on the Japanese islands. Inset displays IGS stations in East Asia, which provide GPS data for network processing in Bernese. Thin and thick contour intervals are $100 \mathrm{~m}$ and $500 \mathrm{~m}$, respectively.

NGII: National Geographic Information Institute

KAIS: Korea Astronomy and Space Science Institute

MOGAHA: The Ministry of Government Administration and Home Affairs MOMAF: Ministry of Maritime Affairs and Fisheries tenna is used at the KHAJ station. Four different receiver types (AOA SNR-8000 ACT, AOA BENCHMARK ACT, ROGUE SNT-8000 and JPS LEGACY) are used for each IGS station (LHAS, KHAJ, TNML and TSKB). We applied the standard IGS Phase Center Variation (PCV) model (TRM29659.00) provided by IGS for all GPS stations.

GPS observation data were analyzed using Bernese GPS software Version 4.2. We also analyzed the data using the GIPSY-OASIS II software (GIPSY, Jet Propulsion Laboratory/ NASA, Zumberge et al. 1997) to investigate the effect of analysis strategy. The precise point positioning (PPP) approach (a Kalman-type filter) is used in GIPSY processing to estimate the ZTD. On the other hand, the Bernese software uses a double difference technique to remove satellite and receiver clock errors and estimates tropospheric delay through least squares inversion (Hofmann-Wellenhof et al. 1992, for example). These differences in the data processing methods may produce software-dependent characteristics in the PW estimation even though similar geophysical and instrumental models and parameter settings are used. A five minute estimation time interval of ZTD was set for GIPSY processing and 30-min time window of ZTD was set for Bernese processing. Notice that the 5-min ZTD interval in GIPSY processing is considered an instantaneous value every 5 minutes. By contrast, Bernese processing estimates the averaged ZTD value during the estimation time window. In order to reduce the PW difference caused by this kind of inconsistency, we compared 30-min averaged PW values derived from GIPSY with values from Bernese processing. Details of analysis strategies, models, and parameters used in analyses and the tropospheric delay estimation are summarized in Table 1. The minimum elevation cutoff angle was set to 15 degrees due to original operational GPS observation settings in the Korean GPS network.

For PW computation using ZTD, surface pressure and temperature at nearby routine surface meteorological stations (mean distance $\sim 4 \mathrm{~km}$ ) were used because no GPS sites used in the study had in situ meteorological sensors. The sea level pressure values were corrected to obtain the actual surface pressure at each GPS station's elevation by assuming 
Table 1 Analysis strategies, models and parameters used in GPS data processing by Bernese and GIPSY software. Same mapping function (Niell dry for initial ZTD and Niell wet for residual ZTD estimation) and ocean tidal loading model (TPXO.6.2) are used in both processing.

\begin{tabular}{|l|c|c|c|}
\hline & Basic strategy & Sampling/Window & Satellite \\
\cline { 3 - 4 } of ZTD (sec) & Netware package & Orwork (Double Difference; DD) & Orblock errors \\
\hline $\begin{array}{l}\text { Bernese GPS } \\
\text { Software Ver. 4.2 }\end{array}$ & PPP (Precise point Positioning) & 300 & JPL final/JPL final \\
\hline GIPSY-OASIS II & PID cancellation \\
\hline
\end{tabular}

hydrostatic equilibrium. The zenith wet delay (ZWD) was derived by subtracting the zenith hydrostatic delay (ZHD) from the ZTD (Bevis et al. 1992), and transformed to PW by

$$
P W=\Pi \bullet Z W D,
$$

and

$$
\Pi=\frac{10^{5}}{R_{v}\left(k_{2}^{\prime}+\frac{k_{3}}{T_{m}}\right)},
$$

where $\Pi$ is a conversion coefficient, which is a function of physical atmospheric constant $R_{v}, k_{2}^{\prime}, k_{3}$ and $T_{m} . R_{v}$ is specific gas constant of water vapor, $k_{2}^{\prime}(17 \pm 10 \mathrm{~K} / \mathrm{hPa})$ and $k_{3}$ $\left((3.776 \pm 0.004) \times 10^{5} \mathrm{~K}^{2} / \mathrm{hPa}\right)$ are constants for the atmospheric refractivity index (Davis et al. 1985). The weighted mean temperature $T_{m}$ was calculated directly from radiosonde soundings using the formula,

$$
T_{m}=\frac{\int \frac{P_{v}}{T} d P}{\int \frac{P_{v}}{T^{2}} d P},
$$

where $P_{v}$ is the partial pressure of water vapor $(h P a), T$ is the temperature of the atmosphere $(K)$. We also calculated $\mathrm{PW}$ using the weighted mean temperature suggested by Bevis et al. 1994. Since the PW derived using $T_{m}$ calculated from radiosonde soundings shows slightly better agreement with radiosonde measurement in terms of standard deviation, we focus on the results using $T_{m}$ calculated directly from radiosonde soundings.

\subsection{Radiosonde}

The locations of radiosonde stations are shown in Fig. 1. Only one radiosonde station is collocated with a GPS site in this study. The horizontal distance between GPS and radiosonde stations are less than $30 \mathrm{~km}$ for all stations and the height difference between them is less than $30 \mathrm{~m}$ except Jeju station, which has a height difference of over $300 \mathrm{~m}$. Information on radiosonde types and the distances and height differences between GPS and radiosonde stations are summarized in Table 2. Twelvehourly radiosonde soundings from Skcho and Jeju stations and 6-hourly soundings from

Table 2 Location of three radiosonde stations and their corresponding GPS stations on the Korean Peninsula. $\mathrm{H}$ is the orthometric height for radiosonde stations, $\Delta \mathrm{H}$ is the height difference between GPS and radiosonde stations (GPS minus radiosonde), and $\Delta \mathrm{L}$ is the horizontal distance between GPS and radiosonde stations.

\begin{tabular}{|c|c|c|c|c|c|c|c|c|c|c|}
\hline $\begin{array}{l}\text { WMO } \\
\text { Code }\end{array}$ & $\begin{array}{c}\text { Launch } \\
\text { Interval } \\
\text { hourly }\end{array}$ & $\begin{array}{c}\text { Station } \\
\text { Name }\end{array}$ & $\begin{array}{c}\text { Sonde } \\
\text { type }\end{array}$ & $\begin{array}{c}\text { Lat. } \\
\text { North }\end{array}$ & $\begin{array}{c}\text { Lon. } \\
\text { East }\end{array}$ & $\begin{array}{c}\mathrm{H} \\
\mathrm{m}\end{array}$ & $\begin{array}{c}\text { GPS } \\
\text { Station }\end{array}$ & $\begin{array}{c}\text { Antenna/ } \\
\text { Radome type }\end{array}$ & $\begin{array}{c}\Delta \mathrm{H} \\
\mathrm{m}\end{array}$ & $\begin{array}{c}\Delta \mathrm{L} \\
\mathrm{km}\end{array}$ \\
\hline 47090 & 12 & Skcho & $\begin{array}{l}\text { Vaisala } \\
\text { RS80 }\end{array}$ & 38.25 & 128.56 & 19 & SKCH & $\begin{array}{l}\text { TRM29659.00/ } \\
\text { Unknown }\end{array}$ & 1.5 & 0 \\
\hline 47185 & 12 & Jeju & $\begin{array}{l}\text { Vaisala } \\
\text { RS80 }\end{array}$ & 33.28 & 126.16 & 73 & JEJU & $\begin{array}{l}\text { TRM29659.00/ } \\
\text { Unknown }\end{array}$ & 331.8 & 28 \\
\hline 47122 & 06 & Osan & $\begin{array}{l}\text { Jin-Yang } \\
1524-511\end{array}$ & 37.10 & 127.03 & 52 & SUWN & $\begin{array}{l}\text { TRM29659.00/ } \\
\text { DOME }\end{array}$ & 31.9 & 19 \\
\hline
\end{tabular}


Table 3 Summary of analysis characteristics related to ZTD estimation used in IGS analysis center for 5-min and 2-hourly ZTD products. Same orbit/clock products (IGS final) and mapping function (Niell dry and wet) are used in all processing. Note that only three IGS individual analysis centers (COD, SIO and JPL) provided ZTD products for 2-hourly IGS products for SUWN and DAEJ stations for two years. Normally, seven ACs contribute their solutions for 2-hourly combined IGS ZTD products.

\begin{tabular}{|c|c|c|c|c|c|}
\hline \multirow{2}{*}{\multicolumn{2}{|c|}{$\begin{array}{l}\text { IGS troposphere } \\
\text { products }\end{array}$}} & \multirow{2}{*}{$\begin{array}{c}\text { GPS data } \\
\text { processing } \mathrm{S} / \mathrm{W}\end{array}$} & \multirow{2}{*}{$\begin{array}{l}\text { Min. Elevation } \\
\text { cutoff angle (deg) }\end{array}$} & \multirow{2}{*}{$\begin{array}{c}\text { Sampling/Window } \\
\text { of ZTD ( } \mathrm{sec})\end{array}$} & $\begin{array}{c}\text { Number of } \\
\text { submissions }\end{array}$ \\
\hline & & & & & SUWN/DAEJ (\%) \\
\hline \multicolumn{2}{|c|}{$5 \mathrm{~min}-\mathrm{ZTD}$} & GIPSY & 7 & 300 & $88.2 / 89.3$ \\
\hline \multirow{3}{*}{$2 \mathrm{hr}-\mathrm{ZTD}$} & $\mathrm{COD}^{* 1}$ & BERNESE & 3 & 7200 & $81.1 / 92.9$ \\
\hline & $\mathrm{SIO}^{* 2}$ & GAMIT & 10 & 3600 & $81.7 / 91.3$ \\
\hline & JPL*3 & GIPSY & 15 & 300 & $26.9 / 12.8$ \\
\hline
\end{tabular}

${ }^{* 1}$ Center for Orbit Determination in Europe, AIUB, Switzerland

*2 Scripps Institution of Oceanography, USA

*3 Jet Propulsion Laboratory/NASA, USA

Osan station are used for a 2-year comparison of PW from GPS and radiosonde measurements.

Considering that radiosonde launch time is usually $30 \mathrm{~min}$ before recorded observation time in operational upper level meteorological observations, we used averaged ZTD values estimated by GIPSY software from $30 \mathrm{~min}$ before 0000 and 1200 UTC (plus 0600 and 1800 UTC for 6-hourly soundings) to calculate GPSderived PW.

\subsection{IGS troposphere products}

Since 1997 the IGS has regularly generated a combined 2-hourly tropospheric product (Gendt 1996). It is based on the submissions of the individual analysis centers (AC), which compute their tropospheric estimates during or after the generation of the IGS final products. The product is the weighted mean of ZTD from the individual submissions. The individual AC biases are calibrated on a weekly basis (Gendt 1996). The product is now available for more than 210 sites. Nearly 150 sites are used by three or more ACs, which allows us to derive reasonable quality measures. The product quality (internal consistency between ACs) is between 3 and $6 \mathrm{~mm}$ in ZTD, which corresponds to less than $1 \mathrm{~mm}$ PW (Gendt 1996).

New 5-min IGS tropospheric products that are completely independent of individual AC contributions have also been provided by IGS (Byun 2005) since early 2003. These products are based on the PPP processing strategy (Zumberge et al. 1997) using the IGS combined final satellite orbit and clock products (Byun 2005).

There are two IGS stations (SUWN and DAEJ) on the Korean Peninsula. Five-min and 2-hourly IGS ZTD products for two years were used to validate the GPS-derived PW from our data processing for the two IGS stations. We also examined the consistency between 5-min and 2-hourly IGS products by comparing PW derived from both IGS products. Analysis characteristics related to ZTD estimation are summarized in Table 3. Since estimation time intervals of ZTD are different for each data set, we used averaged ZTD values for longer time intervals to derive PW for each comparison.

\section{Results}

\subsection{Comparison of GPS-derived PW between Bernese and GIPSY software}

Table 4 summarizes statistical results from comparisons of PW for four GPS stations. In comparing PW from Bernese and GIPSY, biases are small, ranging from $-0.44 \mathrm{~mm}$ to $0.55 \mathrm{~mm}$, except for DAEJ station, which had a bias as high as $2.09 \mathrm{~mm}$ with a standard deviation of $1.47 \mathrm{~mm}$. Standard deviation dependence on site is smaller than that of bias for all stations. 
Table 4 Statistical summary from a comparison between GPS-derived PW derived from Bernese and GIPSY processing in terms of bias (Bernese minus GIPSY) and standard deviation for 2003 and 2004.

\begin{tabular}{|l|c|c|c|c|}
\hline & SUWN & DAEJ & SKCH & JEJU \\
\hline Bias $[\mathrm{mm}]$ & -0.44 & 2.09 & 0.55 & 0.52 \\
\hline SD $[\mathrm{mm}]$ & 1.54 & 1.47 & 1.51 & 1.63 \\
\hline
\end{tabular}

The statistical results show good agreement between Bernese and GIPSY processing except at the DAEJ station. However, the magnitude of bias is more site-dependent than standard deviation. One of possible reasons for this feature, including the relatively large bias at the DAEJ station, is the difference of phase center variation (PCV) characteristics of antennas and/or radomes (Emadson et al. 1998), both of which induce inherent bias in ZTD estimations. Since there has not been an examination of phase characteristics specific to the Korean GPS network, we applied the IGS standard PCV model for GPS stations used in this study. Although the same antenna type (TRM29659.00) was used for the four stations, the radome and monument types are different for each station. In addition, there are several combinations of antenna and radome types in the other four IGS stations (LHAS, TSKB, TNML and KHAJ). It was anticipated that there would be biases in the baseline solutions between Korean GPS and other IGS stations with different antenna types due to the insufficient modeling of antenna phase characteristics in Bernese processing.

In addition, a quality check of GPS observations for multi-path effects (for L1 and L2 pseudo-range) suggests that the DAEJ station has the largest mean value (for L1 and L2) of $0.61 \mathrm{~m}$ among four Korean GPS stations. The mean value of multi-path effects for the SUWN, SKCH, and JEJU stations is less than $0.48 \mathrm{~m}$. Generally, multi-path effect values are greater for Korean GPS stations (including two IGS stations) than for other reference IGS stations (TSKB/0.22 m, LHAS/0.24 m and TNML/ $0.37 \mathrm{~m}$ ), except for the KHAJ station used in Bernese processing. The KHAJ station had the worst quality among all GPS stations used in this study, with a mean value of $1.57 \mathrm{~m}$. This could have affected the baseline solution in our regional processing using Bernese software. However, this effect on ZTD estimation in Bernese processing is not significant. The mean ZTD difference between Bernese processing with and without the KHAJ station is about $1.23 \mathrm{~mm}(\sim 0.19 \mathrm{~mm}$ in $\mathrm{PW})$.

Another possible reason for this bias may involve the different parameter settings used in Bernese and GIPSY processing. The gradient parameter is estimated only in GIPSY processing. The gradient model suggested by MacMillan (MacMillan 1995) is used in GIPSY processing. However, the ZTD differences caused by this kind of inconsistency are minor. The mean difference of ZTD derived from gradient estimation (with gradient estimation-without gradient estimation) is about $0.55 \mathrm{~mm}(\sim 0.09 \mathrm{~mm}$ in PW) in ZTD. ZTD derived from GIPSY processing without the gradient estimation is greater than with gradient estimation, due to the representative errors in the spatial sampling of GPS satellites and the climatological moisture gradient toward the south.

\subsection{Validation of GPS-derived PW using IGS troposphere products}

The statistical results from each comparison for the two IGS stations are summarized in Table 5. The PW estimated from 5-min and 2-hourly IGS ZTD products shows very good agreement (Table 5 column (a)). Biases range from $-0.06 \mathrm{~mm}$ to $-0.22 \mathrm{~mm}$ with standard deviations between $0.55 \mathrm{~mm}$ and $0.62 \mathrm{~mm}$. The IGS 5-min product has a slightly negative bias relative to the IGS 2-hourly product for both stations, and the DAEJ station has better agreement than does the SUWN station.

Columns (b) to (e) in Table 5 show the statistical results from the comparison of GPSderived PW from our own GPS data processing and IGS ZTD products. Overall GPS-derived PW using Bernese and GIPSY software and IGS ZTD products agree reasonably well for three comparison cases. However, there are systematic biases that stem from the data processing software. The mean bias and standard deviation for PW derived from Bernese processing are greater than those from the GIPSY software for the comparison of PW with 5-min IGS products, as shown in column (b) and (e). The 
Table 5 Statistical summary of a comparison between GPS-derived PW and PW estimated from IGS troposphere 5-min and 2-hourly products (5-min minus 2-hourly products, GIPSY/Bernese minus IGS products). Each column ((a) (e)) presents the results for each comparison. $\mathrm{N}$ is the number of data samples.

\begin{tabular}{|c|c|c|c|c|c|c|c|c|c|c|c|}
\hline $\begin{array}{l}\text { GPS } \\
\text { Stn. }\end{array}$ & $\begin{array}{l}\text { Unit } \\
{[\mathrm{mm}]}\end{array}$ & \multicolumn{2}{|c|}{$\begin{array}{l}\text { (a) IGS-5 min } \\
\text { vs IGS-2 hr/N }\end{array}$} & \multicolumn{2}{|c|}{$\begin{array}{l}\text { (b) IGS-5 min } \\
\text { vs GIPSY/N }\end{array}$} & \multicolumn{2}{|c|}{$\begin{array}{l}\text { (c) IGS-2 hr vs } \\
\text { GIPSY/N }\end{array}$} & \multicolumn{2}{|c|}{$\begin{array}{l}\text { (d) IGS-5 min } \\
\text { vs Bernese/N }\end{array}$} & \multicolumn{2}{|c|}{$\begin{array}{c}\text { (e) IGS-2 hr } \\
\text { vs Bernese/N }\end{array}$} \\
\hline \multirow{2}{*}{ suwn } & Bias & -0.22 & \multirow{2}{*}{6,816} & -0.12 & \multirow{2}{*}{30,284} & -0.34 & \multirow{2}{*}{6,909} & -0.92 & \multirow{2}{*}{29,874} & -1.10 & \multirow{2}{*}{6,917} \\
\hline & $\mathrm{SD}$ & 0.62 & & 0.84 & & 0.77 & & 1.54 & & 1.13 & \\
\hline \multirow{2}{*}{ daej } & Bias & -0.06 & \multirow{2}{*}{7,572} & -0.15 & \multirow{2}{*}{30,324} & -0.20 & \multirow{2}{*}{7,679} & 1.49 & \multirow{2}{*}{30,630} & 1.44 & \multirow{2}{*}{7,800} \\
\hline & $\mathrm{SD}$ & 0.55 & & 0.72 & & 0.75 & & 1.39 & & 1.08 & \\
\hline
\end{tabular}

minimum bias of $-0.12 \mathrm{~mm}$ with a standard deviation of $0.84 \mathrm{~mm}$ occurs in a comparison of PW with a 5-min IGS product and GIPSYderived PW at the SUWN station. The maximum bias value (1.49 $\mathrm{mm}$ with $1.39 \mathrm{~mm}$ standard deviation) arises in a comparison of $\mathrm{PW}$ with a 5-min IGS product and Bernese processing at the DAEJ station. These systematic biases depending on data processing software are attributable to biases in Bernese processing caused by the baseline solution for Korean and IGS GPS stations with different antenna, monument and radome types, as mentioned in Section 3.1.

The results of PW derived from Bernese and the IGS-2 hourly product (e) show slightly better bias than in the comparison case (d), except for the SUWN station. The bias for the SUWN station for the comparison case (e) is slightly larger $(0.08 \mathrm{~mm})$ than in the comparison case (d). Considering the different analysis strategy, including software and parameter settings in the data processing for 5-min and 2-hourly IGS ZTD products, these systematic biases are to be expected. As we mentioned in Section 2.3, the IGS 2-hourly troposphere product is a combined solution of ZTD from available individual IGS analysis centers, which compute tropospheric estimates using their own analysis strategies, as summarized in Table 3. Also an irregular number of IGS analysis centers (Table 3) submit their ZTD products every day, which may cause systematic biases. By contrast, the 5-min IGS product is provided by one independent analysis center (Jet Propulsion Laboratory), which computes the ZTD using only the GIPSY software with IGS final orbit and clock information.

\subsection{Comparison of GPS-derived PW with radiosonde measurements}

In light of the better agreement obtained from PW derived from GIPSY processing with IGS products, we focus on the comparison of PW derived from GIPSY processing with radiosonde measurements. Figure 2 displays biases (a) and standard deviations (b) from comparisons of GPS-derived PW using GIPSY software with PW derived from radiosonde soundings from three stations for two years. PW derived from radiosonde measurement shows dry bias relative to GPS-derived PW for all stations. The mean bias of the GPS-derived PW compared with 12-hourly radiosonde measurements from three stations is $1.50 \mathrm{~mm}$, and the standard deviation is $2.45 \mathrm{~mm}$. Biases range from $1.06 \mathrm{~mm}$ to $1.86 \mathrm{~mm}$ (for 'All' in Fig. 2a). These results show better agreement, in terms of rms difference, between GPS and radiosonde observations than previous research performed in other humid regions (Ohtani et al. 2000; Liou et al. 2001). However, these statistical results are somewhat poorer than those obtained by a comparison with water vapor radiometer measurement in dry regions, like central North America (1-2 mm) (Rocken et al. 1995; Duan et al. 1996; Emardson et al. 1998; Tregoning et al. 1998).

The JEJU station has a relatively higher bias than do other stations. This may be due to the large difference of horizontal distance and height between GPS and radiosonde stations as shown in Table 2. This feature is also connected with a strong local climate on Jeju Island caused by geographic location and topography. Jeju is a small island located in the most southern part of Korea (Fig. 1), and the 

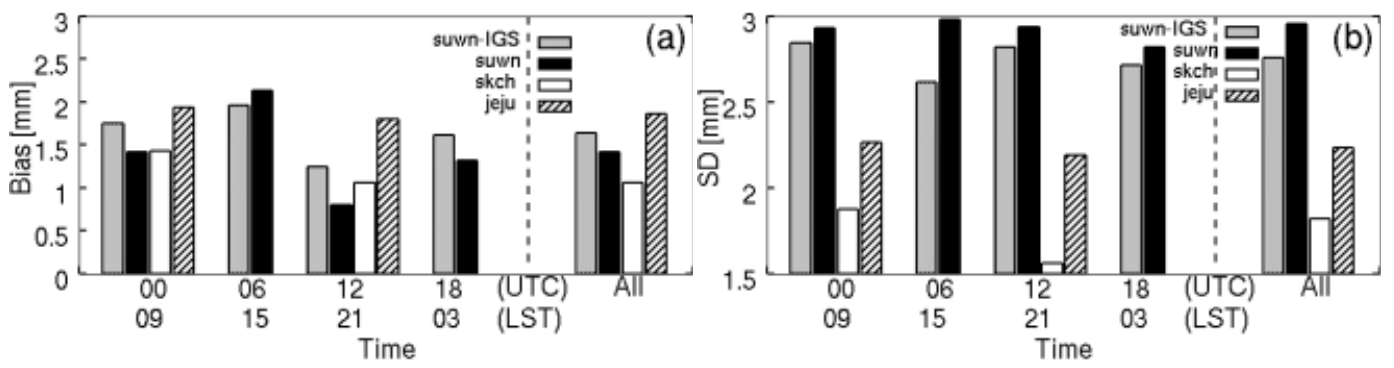

Fig. 2. (a) Bias (GPS minus radiosonde) and (b) standard deviation for PW derived from GPS and radiosonde observations. Horizontal axis presents each radiosonde launch time with 6-hour intervals, and 'All' on the axis indicates averaged value of bias and standard deviation for all available radiosonde launch times. Gray boxes indicate statistical results from IGS 5-min ZTD products for the SUWN IGS station. Other boxes indicate the results from our own data processing for three different GPS stations. Black boxes are for SUWN, white boxes are for SKCH, and boxes with diagonal lines are for JEJU station.

climate is closer to subtropical than extratropical and is much more humid than the other regions of Korea. Further investigations are needed to better understand this local feature of GPS-derived PW over Jeju.

It is also interesting that the SUWN station, which is close to the Osan radiosonde station, shows the best agreement with radiosonde measurements among the three stations in terms of bias, even though GPS and radiosonde stations are not collocated there. It is notable that comparison results from ZTD derived from our GIPSY processing show better agreement with radiosonde-derived PW than PW derived from IGS 5-min products in terms of bias for the SUWN station (Fig. 2a). SKCH is the only GPS station collocated with a radiosonde (Table 2). Because the two radiosonde stations used different types of radiosonde equipment, it is possible that the systematic bias is due to the radiosonde type. We used radiosonde data from Vaisala RS80 humidity sensors for Skcho and Jeju stations and JINYANG 1524-511 (JINYANG Industrial Co. Ltd. 2006) for the Osan station. The dry bias error of humidity measurements from old Vaisala products (RS 80) has been reported (Wang et al. 2002; Nakamura et al. 2004), and it is also attributable to the radiosonde launching time related to solar heating of the humidity sensor.

To investigate this kind of systematic bias of radiosonde measurements, we also examined the statistics for each available radiosonde launching time (0000 (0900 LST) and 1200
UTC (2100 LST)). Consistent with previous reports, dry biases for all day time (0900 LST) radiosonde stations measurements are systematically greater than in the night (2100 LST) (Fig. 2 ). Figure 2 shows similar results for each time for SUWN-IGS and SUWN (our processing), suggesting that the $\mathrm{PW}$ difference derived from our processing and IGS products is relatively minor, as mentioned in Section 3.2.

Especially for SUWN GPS station, we investigated the systematic bias by using relatively high temporal resolution radiosonde soundings with 6-hour (0000, 0600, 1200 and 1800 UTC (0900, 1500, 2100 and 0300 LST)) time intervals for two years. Similar to the comparison results from 12-hourly radiosonde measurements, larger negative biases of PW from radiosonde sounding occurred during the day time (0900 and 1500 LST), as shown in Fig. 2. The maximum bias value of $2.13 \mathrm{~mm}$ is 1500 LST with a standard deviation of $2.98 \mathrm{~mm}$, and the minimum bias value of $0.79 \mathrm{~mm}$ is $2100 \mathrm{LST}$ with a standard deviation of $2.93 \mathrm{~mm}$. This result also clearly demonstrates the solar heating effect on large dry bias of radiosonde measurements in the daytime. This feature is evident in Fig. 3, showing the relationship between the difference of $\mathrm{PW}$ and the absolute amount of PW calculated from 6-hourly radiosonde measurements at the SUWN GPS stations (GPS minus radiosonde). In addition, the $\mathrm{PW}$ difference (GPS minus radiosonde) is positively correlated with the amount of water vapor (PW). This trend is more significant during the day- 

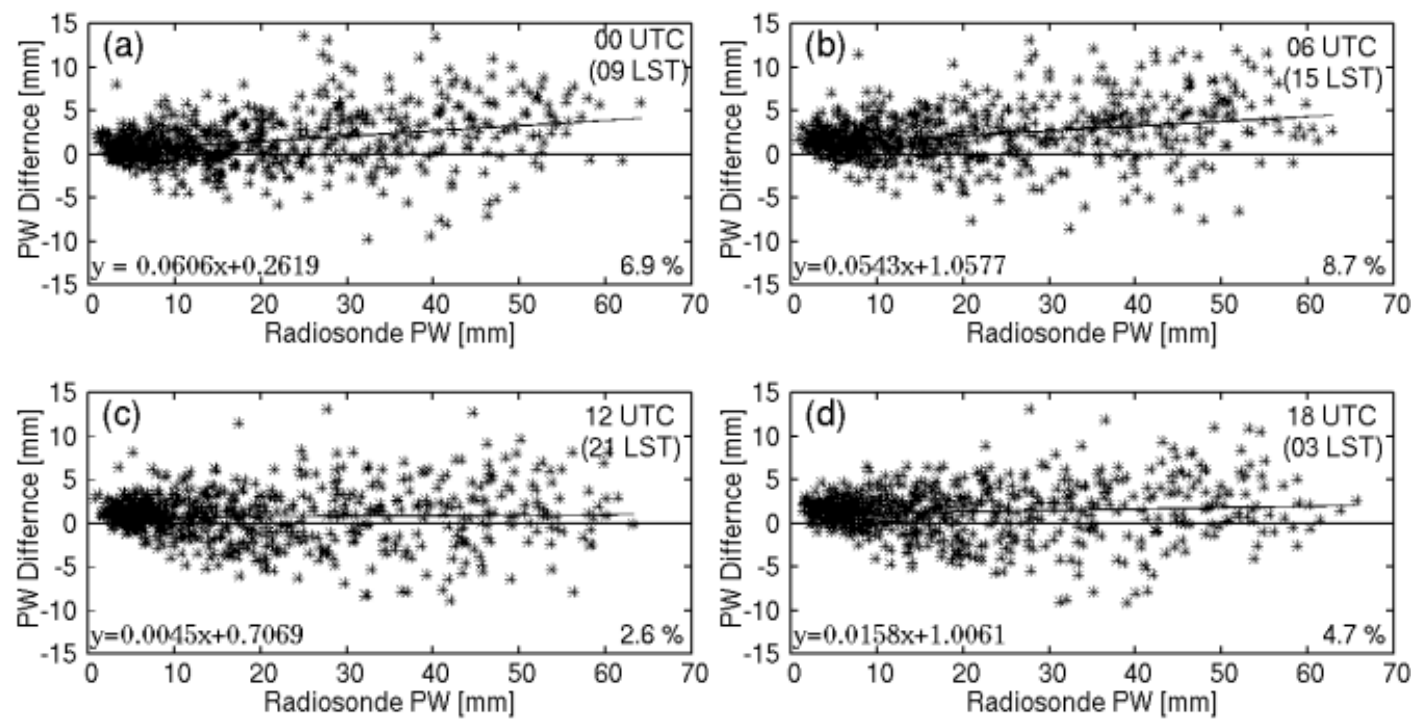

Fig. 3. Scatter plots for difference between GPS-derived PW and radiosonde PW (GPS minus radiosonde) at the SUWN GPS station. Each figure shows 6-hourly radiosonde launch times at (a) 0000, (b) 0600, (c) 1200 and 1800 UTC. Radiosonde launch times (0000 and 0600 UTC) for (a) and (b) are local day time and 1200 and 1800 UTC for (c) and (d) are local night time. The number on the right bottom of each figure shows the PW scale dry error depending on the amount of PW. The lines in each figure indicate regression lines.

time. The relative PW difference (GPS minus radiosonde) range from $2.6 \%$ at $2100 \mathrm{LST}((\mathrm{c}))$ to $8.7 \%$ at $1500 \operatorname{LST}((\mathrm{b}))$.

This issue was evaluated in more detail. Figure 4 displays biases and standard deviations for PW at 0900 and 2100 LST from GPS and radiosonde observations depending on the amount of PW from radiosonde measurements for three stations. The bias increased for large amounts of PW can be clearly seen in the daytime, except in high ranges of $\mathrm{PW}$ over approximately $40 \mathrm{~mm}$ at the JEJU station in Fig. 4a. The JEJU station shows a different pattern of decreasing bias with PW over $40 \mathrm{~mm}$. This is attributed to large differences in horizontal distance and height between the GPS and radio-
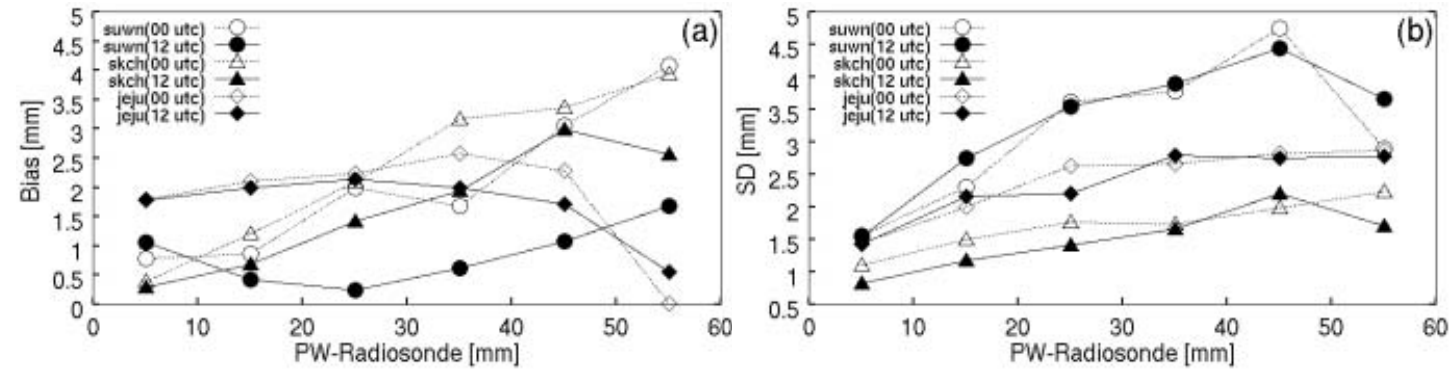

Fig. 4. (a) Bias (GPS minus radiosonde) and (b) standard deviation for PW derived from GPS and radiosonde measurements at 0000 UTC and 1200 UTC as a function of PW. Bias and standard deviation are computed with $10 \mathrm{~mm}$ PW bins derived from radiosonde soundings. Open symbols with dotted lines present error statistics for the daytime, while filled symbols with solid lines present those for the night time. 

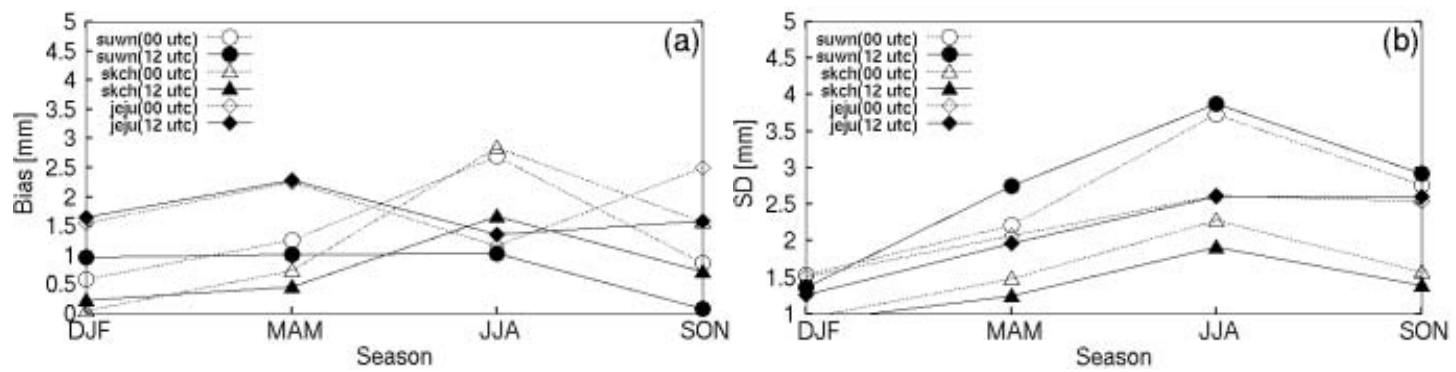

Fig. 5. (a) Bias (GPS minus radiosonde) and (b) standard deviation for PW derived from GPS and radiosonde measurements at 0000 and 1200 UTC as a function of season. DJF (December, January and February), MAM (March, April and May), JJA (June, July and August) and SON (September, October and November) indicate four seasons. Open symbols with dotted lines present error statistics for the daytime, while filled symbols with solid lines present those for the night time.

sonde stations and to strong local climate on Jeju Island, as mentioned before. There is no clear trend that the bias increases as the PW increases during the nighttime, with the exception of the SKCH station. Each station shows different patterns of bias dependency on the amount of nighttime PW. The standard deviation tends to increase more in humid conditions than does the bias during both the day and night as shown in Fig. 4b. Bias and standard deviation decrease slightly in the range over $50 \mathrm{~mm}$.

These results are consistent with other reports showing that the agreement between PW from GPS and water vapor radiometer measurements decreases with the total water vapor burden (Liou et al. 2000; Liou et al. 2001; Kopken el al. 2001). In addition, this result also confirmed that most of the bias between GPS and radiosonde measurements comes from the dry bias of radiosondes in the daytime. In connection with this issue, we also examined the seasonal dependency of error statistics of GPSderived PW for two years. Figure 5 shows the statistical results for PW derived from GPS and radiosonde measurements at 0900 and 2100 LST as a function of season. Similar to the results in Fig. 4, bias and standard deviation generally increase with large amounts of PW and standard deviation shows more obvious seasonal dependency for both day and night time. The maximum bias and standard deviation values are in summer (JJA, seasonal mean PW for three stations $\sim 38.3 \mathrm{~mm}$ ) except for the JEJU station bias. In addition, dry bias in- creased during the day in the humid season, except for the JEJU station. By contrast, there is no obvious relationship between the bias and the amount of PW during the nighttime.

\section{Possible errors in GPS-derived PW caused by multi-path effects}

Some errors in GPS-derived PW (ZTD) are expected to be caused by the multi-path and/or insufficient PCV modeling. ZTD estimates can be contaminated by these errors and cause biases.

Figure 6 shows the post-fit phase residuals of the linear combination of the L1 and L2 GPS phase measurements carrier wave (L3) depending on the elevation angle obtained from GIPSY processing for two Korean regional network stations (SKCH and JEJU) and for two IGS stations (SUWN and DAEJ) for 2004. The post-fit residuals were stacked, and the mean value for each site was obtained, with a resolution of $1^{\circ} \times 1^{\circ}$ for azimuth and elevation angles, respectively. In particular, the IGS stations used uncommon monument types, and each monument type is different. The SKCH and JEJU stations used a monument type similar to GEONET (GSI4 type). The residual in Fig. 6 clearly shows systematic wavy patterns dependent on elevation angle. These systematic patterns are evidence of un-modeled phase center variations. The stations which use similar monument types show similar systematic patterns with slightly different amplitude. It is suggested that the phase center variations are mainly caused by multi-path effects, dependent 

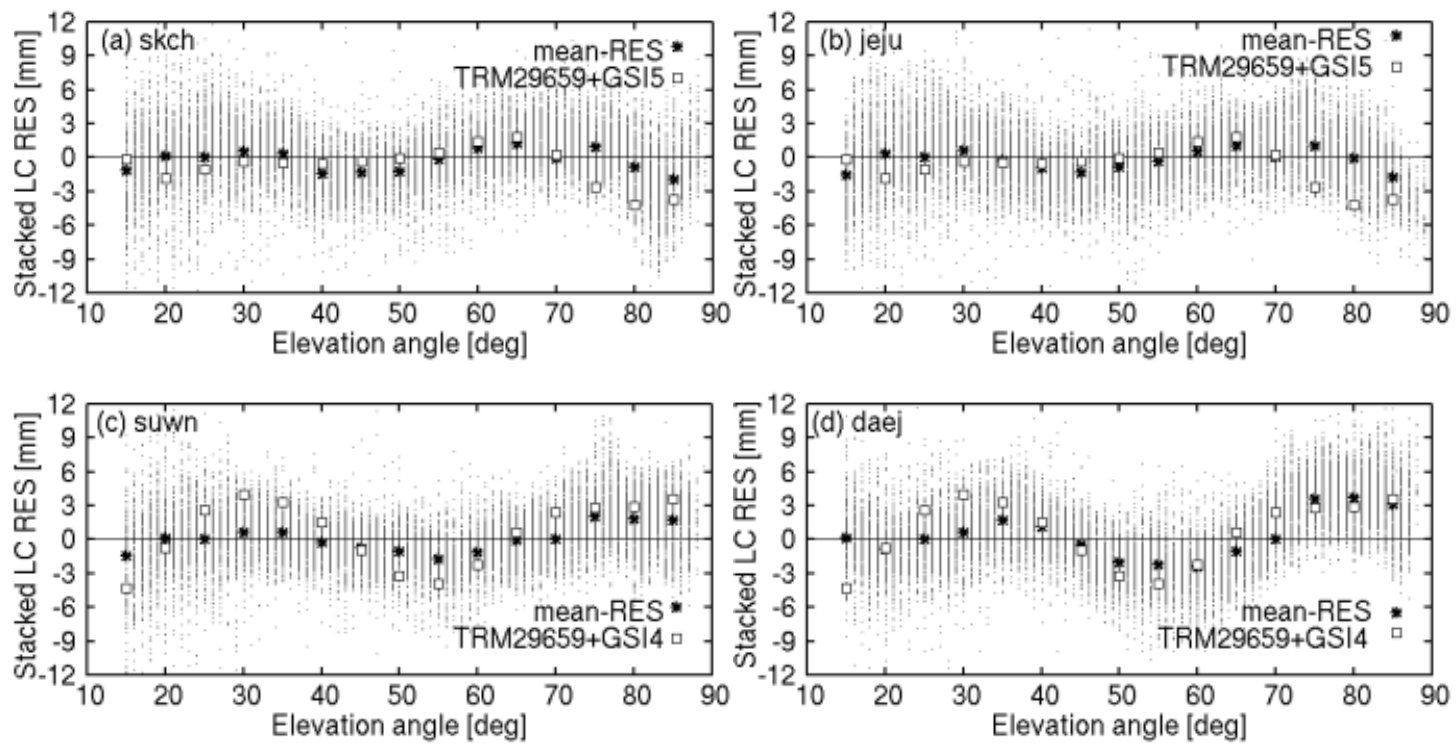

Fig. 6. The post-fit phase residual of the L3 (linear combination of the L1 and L2 phase measurements) distributions depend on elevation angle for two non-IGS GPS stations (SKCH and JEJU, top panels) and two IGS-stations (SUWN and DAEJ, bottom panels) for the year of 2004. The standard IGS PCV model (TRM29659.00) is applied for all stations. Black dots indicate the post-fit phase residual for each azimuth angle, and black stars show the mean value of residuals in the range of 5-degree elevation angles. Square points represent phase variation from GEONET PCV model for reference purpose (TRM29659+GSI5 in (a) and (b), TRM29659+GSI4 in (c) and (d)).

on the monument types. One of most important differences between each monument type used in this study is the pillar top structure. This difference can produce different multi-path environments depending on the height between the antenna phase center and the antenna basement, which changes the pattern of synthetic waves.

Hatanaka et al. (2001) also showed that both phase characteristics of radomes and the multipath from the metal plate at the top of the station pillars distort the antenna phase characteristics, and those significantly affect GEONET solutions if the PCV model developed for GEONET monuments is not applied. Consistent with this result, the DAEJ station $((\mathrm{d}))$, which uses a relatively wide plate at the top of the pillar, different from the other three stations, shows the strongest residual variation dependent on elevation angle. Because the choke ring antenna should not have such strong elevation dependent offsets, it is likely that most of the phase center variations in the residual map came from the multi-path effect of reflected signals from the antenna basement.
Thus, the development of the PCV model for specific monuments, including the two IGS stations, is needed to obtain a more accurate PW.

To investigate the ZTD error caused by multipath effects, we estimated the ZTD error. We first made a residual stacking map with resolution of $1^{\circ} \times 1^{\circ}$ and then computed slant delay error using multi-path stacking maps and real satellite position information. Finally, we derived ZTD error by averaging slant delays mapped into zenith direction epoch by epoch. In our calculation of ZTD errors, the residual bias reaches a maximum of $4.59 \mathrm{~mm}$ in zenith direction for the SKCH station, which is equal to about $0.72 \mathrm{~mm}$ of PW. The biases of residuals in zenith direction for the other three stations are less than $2.72 \mathrm{~mm}(\sim 0.42 \mathrm{~mm}$ in $\mathrm{PW})$. However, this bias did not show seasonal and annual variations. Since the bias caused by multi-path effect is an absolute amount and not dependent on the total PW amount, such as dry bias in radiosonde measurements, the bias is relatively small in larger PW cases, and can thus be negligible for the large PW amounts during heavy rainfall periods. For se- 
vere rainfall forecasts, dry biases of radiosonde measurements are a much more significant error source than the error discussed above.

As mentioned in Section 2.1, Korean GPS networks use monuments similar to those used in GEONET. In Fig. 6, the residual patterns are similar to the phase variations in the GEONET PCV model (square points). This suggests the possibility of ZTD bias correction by applying the GEONET PCV. We applied the GEONET PCV model, which is the closest to the residual patterns from the Korean GPS stations, but no significant improvements were found. This suggests that we need to develop original PCV models for Korean and IGS GPS stations on the Korean Peninsula.

\section{Summary}

PW derived from ground-based GPS measurements in the Korean GPS network were compared with radiosonde measurements for two years. Characteristics of GPS-derived PW estimated by two different types of software (Bernese and GIPSY) were compared to check differences dependent on analysis strategy. PW derived from our GPS data processing were also validated using IGS 5-min and 2-hourly troposphere products.

Significant systematic biases were not found in comparison of PW derived from Bernese and GIPSY processing. However, we found bias dependency on site, likely resulting from the biases in the network solutions using Korea GPS and other IGS stations with different antenna, radome and monument types due to the insufficient modeling of antenna phase characteristics in Bernese processing.

In a comparison of GPS-derived PW from our analysis with IGS 5-min and 2-hourly products, a reasonable consistency was shown in all comparison cases. However, there are systematic biases that depend on analysis strategies. PW derived from GIPSY software showed better agreement (mean bias of $-0.14 \mathrm{~mm}$ and standard deviation of $0.78 \mathrm{~mm}$ ) with IGS 5-min products than those from Bernese processing. In addition, PW from Bernese processing showed better agreement with IGS 2-hourly products than IGS 5-min products. This feature is mainly attributable to the analysis strategy and parameter setting consistency between Bernese and GIPSY software in our process- ing and IGS ZTD products. However, the PW bias derived from Bernese processing and IGS 2 -hourly products is relatively not small. One possible reason for this is the inconsistency of the PCV model used in our Bernese processing and individual IGS analysis centers. Biases in Bernese processing caused by the baseline solution between Korea and IGS GPS stations with different types of antennas, monuments and radomes could also contribute to the inconsistency. Further studies on this issue are needed.

The PW derived from radiosonde measurement shows dry bias relative to GPS-derived $\mathrm{PW}$. The mean bias of GPS-derived PW is $1.50 \mathrm{~mm}$ with a standard deviation of $2.45 \mathrm{~mm}$. This result shows better agreement between GPS and radiosonde measurements than those obtained in other humid regions $(3.7 \mathrm{~mm} \mathrm{rms}$ difference), but show less agreement than those obtained in central North America (1-2 mm rms difference) compared with water vapor radiometer observations. This may reflect strong local temporal and spatial water vapor variability on the Korean Peninsula compared with other regions.

We also found systematic dry biases of radiosonde measurements depending on the radiosonde launch time. The dry bias for the daytime (0900 LST) was systematically larger than that for the nighttime (2100 LST). This result is consistent with the findings of Wang et al. (2002), in which the dry bias of the Vaisala radiosonde (RS 80) humidity measurements was shown to be caused by the daytime radiational heating of the humidity sensor. This issue was confirmed with 6-hourly radiosonde observations at Osan, where the maximum bias value occurred at $1500 \mathrm{LST}$ and the minimum value at $2100 \mathrm{LST}$. In addition, we have shown the dependency of error statistics both on PW and season. Moreover, we found that the bias and standard deviation were positively correlated with PW and increased in the summer and that standard deviation tends to increase more in humid conditions than do biases both in day and night time.

The errors in GPS-derived PW caused by multi-path effects related to monument types in the Korean GPS network are also shown in this study. The bias of residuals reaches $4.59 \mathrm{~mm}(\sim 0.72 \mathrm{~mm}$ in $\mathrm{PW})$ in the zenith direction. This result suggests that specific phase 
correction for each monument type in the network is necessary for more accurate PW estimates, especially in smaller PW.

Our results show the accuracy of GPSderived PW with reasonable quality on the Korean Peninsula, which is subject to extreme variability of water vapor due to the influence of Asian monsoons. These results suggest the promise of GPS-derived PW from the Korean GPS network for application in various meteorological fields, such as numerical weather prediction, climate studies and validation of PW from other remote sensing techniques, including correction of the dry bias of radiosonde measurements. PW derived from the regional Korean GPS network can also contribute to global meteorological studies, such as the IGS network stations. However, considering that the accuracy of radiosonde is critical for discussing the difference of the error statistics in this study, comparisons using additional independent observations, such as microwave radiometers, are required in further investigations.

\section{Acknowledgements}

We would like to acknowledge the support from the Korea Foundation for the International Cooperation Research Program of the Ministry of Science \& Technology (KICOS) through a grant provided by the Korean Ministry of Science \& Technology (MOST) (No. K2 0607010001-07A050100110) to the Synoptic Scale Meteorology Group of Seoul National University. This program was also partly supported by the Global Partnership Program and the Brain Korea 21 Project. The National Science Foundation (NSF) through grants ATM-9977639 and ATM-031588 supported this study. We thank John Braun and Teresa Van Hove (COSMIC/UCAR) for helping us with Bernese processing and for engaging with us in constructive discussions. We also thank Dr. Bill Kuo of UCAR COSMIC Project for his support of GPS research to Synoptic Scale Meteorology Group. The authors owe a great debt to many people, including two anonymous reviewers, who read the first draft and presented us with many improvements for this work.

\section{References}

Byun, S.H., Y. Bar-Server, and G. Gendt, 2005: The new tropospheric product of the international
GNSS service. Proceedings ION GNSS $18^{\text {th }}$ International Technical meeting of the Satellite Division, 13-16 September 2005, Long Beach, CA.

Bevis, M., S. Businger, T.A. Herring, C. Rocken, R.A. Anthes, and R.H. Ware, 1992: GPS Meteorology: Remote sensing of atmospheric water vapor using the Global Positioning System. J. Geophys. Res., 97, 15787-15801.

Beutler, G., E. Brockmann, R. Dach, P. Fridez, W. Gurtner, U. Hugentobler, J. Johnson, L. Mervart, M. Rothacher, S. Schaer, T. Springer, and R. Weber, 2000: Bernese GPS software version 4.2. Astronomical Institute, University of Berne, $436 \mathrm{pp}$.

Davis, J.L., T.A. Herring, I.I. Shapiro, A.E.E. Rogers, and G. Elgered, 1985: Geodesy by ratio interferometry: Effects of atmospheric modeling errors on estimates of baseline length. Radio. Sci., 20, 1593-1607.

Duan, J., M. Bevis, P. Fang, Y. Bock, S. Chiswell, S. Businger, C. Rocken, F. Solheim, T. Van Hove, R. Ware, S. McClusky, T.A. Herring, and R.W. King, 1996: Meteorology: Direct estimation of the absolute value of precipitable water. $J$. Appl. Meteorol., 35, 830-838.

Dietrich, S.V.R., K.-P. Johnsen, J. Miao, and G. Heygster, 2004: Comparison of tropospheric water vapor over Antarctica derived from AMSU-B data, ground-based GPS data and the NCEP/NCAR reanalysis. J. Meteor. Soc. Japan, 82, 259-267.

Emardson, T.R., G. Elgered, and J. Johansson, 1998: Three months of continuous monitoring of atmospheric water vapor with a network of GPS receivers. J. Geophys. Res., 103, 1807-1820.

Gendt, G., 1996: Comparisons of IGS tropospheric estimates. Proceedings of IGS Analysis Center Workshop, 19-21 March 1996 Silver Spring, Maryland USA, Eds. R.E. Neilan, P.A. Van Scoy, J.F. Zumberge, 151-164.

Gradinarsky, L.P., J.M. Johansson, H.R. Bouma, H.G. Scherneck, and G. Elgered, 2002: Climate monitoring using GPS. Phys. Chem. Earth, 27, 335-340.

Gutman, S.I., K.L. Holub, S.R. Sahm, J.Q. Stewart, T.L. Smith, S.G. Benjamin, and B.E. Swartz, 2003: Rapid retrieval and assimilation of ground based GPS-met observations at the NOAA Forecast Systems Laboratory: Impact on weather forecasts. Proceeding of International Workshop on GPS Meteorology, Tsukuba, Japan, Japan Meteorological Agency, 112-1-1-12-10.

Hatanaka, Y., M. Sawada, A. Horita, M. Kusaka, 2001: Calibration of antenna-radome and mon- 
ument-multipath effect of GEONET-Part 1: measurement of phase characteristics. Earth Planet and Space, 53, 13-21.

Hofmann-Wellenhof, B., H. Lichtenegger, and J. Collins, 1992: GPS Theory and Practice, SpringerVerlag Wien, $355 \mathrm{pp}$.

Iwabuchi, T., I. Naito, and N. Mannoji, 2000: A comparison of Global Positioning System retrieved precipitable water vapor with the numerical weather prediction analysis data over the Japanese Islands. J. Geophys. Res., 105, 45734585.

JINYANG Industrial Co. Ltd., 2006: Operation manual of electronic meteorological observation equipments, 4 (in Korean).

Kopken, C., 2001: Validation of integrated water vapor from numerical models using ground-based GPS, SSM/I, and Water Vapor Radiometer measurements. J. Appl. Meteor., 40, 11051117.

Kuo, Y.-H., Y.-R. Guo, and E.R. Westwater, 1993: Assimilation of precipitable water measurements into a mesoscale numerical model. Mon. Wea. Rev., 121, 1215-1238.

Liou, Y.-A., C.-Y. Huang, and Y.-T. Teng, 2000: Precipitable water observed by ground-based GPS receivers and microwave radiometery. Earth Planets and Space, 52, 445-450.

Liou, Y.-A., Y.-T. Teng, T. Van Hove, and J.C. Liljegren 2001: Comparison of precipitable water observations in the near tropics by GPS, microwave radiometer, and radiosondes. J. Appl. Meteorol., 40, 5-15.

MacMillan, D.S., 1995: Atmospheric gradients from very long baseline interferometry observations. Geophys. Res. Lett., 22, 1041-1044.

Nakamura, H., H. Seko, and Y. Shoji, Aerological Ob- servatory, Meteorological Instruments Center, 2004: Dry biases of humidity measurements from the Vaisala RS80-A and Meisei RS2-91 Radiosondes and from ground-based GPS. $J$. Meteor. Soc. Japan, 82, 277-299.

Ohtani, R. and I. Naito, 2000: Comparisons of GPSderived precipitable water vapors with radiosonde observations in Japan. J. Geophys. Res., 105, 26917-26930.

Rocken, C., R. Ware, T. Van Hove, F. Solheim, C. Alber, J. Jhonson, M. Bevis, and S. Businger, 1993: Sensing atmospheric water vapor with the Global Positioning System, Geophys. Res. Lett., 20, 2631-2634.

Rocken, C., T. Van Hove, J. Johnson, F. Solheim, and R. Ware, 1995: GPS/STORM-GPS sensing of atmospheric water vapor for meteorology. $J$. Atmos. Oceanic Technol., 12, 468-478.

Tregoning, P., R. Boers, D. O'Brien, and M. Hendy, 1998: Accuracy of absolute precipitable water vapor estimates from GPS observations. $J$. Geophys. Res., 103, 28701-28710.

Wang, J., H.L. Cole, D.J. Carlson, E.R. Miller, and K. Beierle, 2002: Corrections of humidity measurement errors from the Vaisala RS80Radiosonde-Application to TOGA COARE data. J. Atmos. Oceanic Technol., 19, 981-1002.

Yuan, L., R. Anthes, R. Ware, C. Rocken, W. Bonner, M. Bevis, and S. Businger, 1993: Sensing global climate change using the Global Positioning System. J. Geophys. Res., 98, 1492514937.

Zumberge, J.F., M.B. Heflin, D.C. Jefferson, M.M. Watkins, and F.H. Webb, 1997: Precise point positioning for the efficient and robust analysis of GPS data from large networks. J. Geophys. Res., 102, 5005-5017. 